\title{
Glyphosate Effect: Has the Glyphosate Controversy Affected the EU's Regulatory Epistemology?
}

\author{
Marta MORVILLO*(1)
}

\begin{abstract}
Glyphosate's authorisation will expire in 2022 and its re-approval will take place in a changed legal and political landscape: the national phase of risk assessment is entrusted to a taskforce of four Member States, and, from 2021, the reform of the general food law will apply, imposing, inter alia, more ambitious transparency standards. Taking stock of these developments, this contribution analyses, from a legal perspective, whether and how the glyphosate dispute has contributed to the development of the EU's regulatory epistemology, with specific regard to food governance. It identifies the "manifesto" of the EU's regulatory epistemology in the 2002 guidelines on the collection and use of expertise and reads them in the light of the glyphosate dispute. In particular, it focuses on the legal arrangements reflecting the principles established in the 2002 guidelines (quality, openness, effectiveness) and analyses them against the tensions that emerged throughout the dispute with regard to the sources, levels and purposes of EU regulatory knowledge-making. It then considers whether and how such tensions have been addressed by legislative reform and whether this has resulted in a further refinement of the EU's regulatory epistemology.
\end{abstract}

\section{INTRODUCTION AND OUTLINE}

The reauthorisation of glyphosate has triggered one of the most acute crises in EU food governance over - at least - the last decade. The amount and extent of societal, political, scientific and legal contestation it has prompted is unprecedented. ${ }^{1}$ While the European Commission was struggling to have its draft implementing regulation approved by Member States' (MS) representatives in the standing committee on Plants, Animals, Food and Feed (PAFF), a variety of avenues of contestation mobilised. One of the

\footnotetext{
Amsterdam Centre for European Law and Governance, University of Amsterdam; email: m.morvillo@uva.nl. My research in this field has been supported by a Marie Skłodowska-Curie grant on "The Constitutional Place of Expertise" (CONPLEX), funded under the European Union Horizon 2020 research and innovation programme (grant agreement No. 748463). I would like to thank the participants to the workshop "The science and politics of glyphosate", Rotterdam, 6 June 2019, Alessandra Arcuri, Yogi Hendlin, Mario Pagano and the anonymous reviewer for their encouraging and insightful feedback. All mistakes, of course, remain mine.

1 See A Arcuri and YH Hendlin, "The Chemical Anthropocene: Glyphosate as a Case Study of Pesticide Exposures" (2019) 30 King's Law Journal 234. 
few successful European Citizens Initiatives (ECIs) was presented, asking to ban glyphosate from the European market. In the meantime, the European Parliament (EP) approved two resolutions and established a special committee (the Special Committee on EU authorisation procedure for pesticides (PEST)) to review the whole pesticides authorisation procedure in light of the glyphosate dispute. Finally, several complaints were brought to the European Ombudsman, petitions to the EP and cases to the Court of Justice of the European Union (CJEU).

The glyphosate saga can be seen either as a fortuitous but perfect storm or as a crisis long foretold. On the one hand, it resulted from the conflation of a series of factors specific to the substance under examination: its wide use globally, the disagreement between the European Food Safety Authority (EFSA; followed by the European Chemicals Agency (ECHA)) and the International Agency for Research on Cancer (IARC) over its carcinogenicity, and the "Monsanto papers" released in the context of US-based lawsuits against glyphosate's first synthesiser and main producer, suggesting industry's influence over scientific studies concerning the substance's safety, all contributed to glyphosate's reputation. On the other hand, far from having happened in a vacuum, the controversy over the active substance is deeply rooted in the conflicts and tensions that have haunted EU risk regulation in general, and food governance in particular, since its very inception. The constitutive role expert knowledge plays in the justification of regulatory decisions at the EU level, ${ }^{2}$ the accountability gaps affecting expert-based decisions due to their complexity and to their apparent value-neutrality, ${ }^{3}$ and the struggle of EU risk assessors (EFSA) and managers (the European Commission) to gain European citizens' trust ${ }^{4}$ all lingered in the background of the glyphosate dispute. As a result, its meaning transcends the individual case, speaking to broader issues of the legitimacy and accountability of EU risk regulation.

Glyphosate will soon be back under the scrutiny of EU regulatory authorities, its authorisation expiring at the end of 2022. Compared to the previous assessments, the next reauthorisation of the active substance will take place in a changed legal and political landscape. The national phase of risk assessment will be entrusted to a taskforce of four Rapporteur Member States (RMS), and, starting from 2021, the reform of the general food law will apply, imposing, inter alia, new and more ambitious transparency standards - although not as ambitious as those established by the General Court in its recent judgments in the Tweedale and Hautala cases.

Taking stock of these developments, this contribution analyses, from a legal perspective, whether and how the glyphosate dispute has contributed to the development of the EU's regulatory epistemology, with specific regard to food governance. Has anything changed in the way EU regulators approach the production

2 S Jasanoff, "Constitutions of Modernity: Science, Risk and Governable Subjects" in M Weimer and A De Ruijter (eds), Regulating Risks in the European Union: The Co-production of Expert and Executive Power (Oxford, Hart 2017), p 33.

3 M Weimer and A De Ruijter, "Regulating Risks in the European Union: The Coproduction of Expert and Executive Power" in Weimer and De Ruijter, supra, note 2, p 8.

4 E Vos and M Everson (eds), Uncertain Risks Regulated (Abingdon, Routledge 2009), p 251. 
and evaluation of regulatory science? Or is it rather a situation where continuity has prevailed over discontinuity?

Section II defines the concept of regulatory epistemology and identifies its cornerstones in the EU context in risk analysis and in the principles of the openness, quality and effectiveness of scientific advice. Section III argues that the glyphosate dispute has put such cornerstones under strain along three lines, namely the sources, levels and purposes of EU regulatory knowledge-making. It characterises these lines of tension through the analysis of regulatory-scientific and political input generated in the context of the glyphosate dispute and shows that these tensions cut across the lines of risk assessment and risk management. Section IV analyses how such tensions have been addressed through legislative reform. It shows that they have only been addressed from a risk assessment perspective, thus failing to acknowledge the tensions affecting risk management and, even more, the close intertwinement between the two. Section V concludes, arguing that while the glyphosate dispute has not resulted in major developments in the EU's regulatory epistemology, it has, however, exposed and questioned some of its basic assumptions, thus opening up a space for future change.

\section{Regulatory EPISTEMOlOGy in EU FOOD GOVERnANCE: RISK ANALysis, PRECAUTION AND THE VIRTUES OF EXPERT ADVICE}

The concept of regulatory epistemology has been coined in the context of science and technology studies, ${ }^{5}$ as a specification of the broader concept of civic epistemology. ${ }^{6}$ The former focuses on a given regulatory context, the latter on societies at large, and both concepts build on the assumption of the culture-sensitive nature of knowledge production. In particular, is has been highlighted how societies and institutions have been developing expectations and shared understandings as to what requirements science-based claims should fulfil in order to be accepted as authoritative and credible, and thus adequate bases for public deliberation. ${ }^{7}$ Civic epistemologies embody how such expectations are articulated through "institutionalised practices by which members of a given society test and deploy knowledge claims used as a basis for making collective choices". 8 Although the practices through which civic epistemologies manifest themselves do not necessarily correspond to formal rules, they are often institutionalised by way of hard or soft law. ${ }^{9}$ Such rules address, for example, the modes of participation in public knowledge-making, the availability of accountability mechanisms, the accepted standards of objectivity and the rules

\footnotetext{
5 DE Winickoff and DM Bushey, "Science and Power in Global Food Regulation: The Rise of the Codex Alimentarius" (2010) 35(3) Science, Technology, \& Human Values 356, 360; the concept has been further developed by A Arcuri, "Global Food Safety Standards: The Evolving Regulatory Epistemology at the Intersection of the SPS Agreement and the Codex Alimentarius Commission" in P Delimatsis (ed), The Law, Economics and Politics of International Standardisation (Cambridge, Cambridge University Press 2015) p 79.

6 S Jasanoff, Designs on Nature: Science and Democracy in Europe and the United States (Princeton, NJ, Princeton University Press 2007).

7 ibid, 249.

8 ibid, 250. See also 271.

9 ibid, 250.
} 
concerning what counts as expertise. ${ }^{10}$ A particular subtype of civic epistemologies can be encountered in the narrower context of a specific regulatory setting, such as an expert regulatory body. The term "regulatory epistemologies" has been coined by Winickoff and Bushey precisely to hint at the development of norms and practices for the management of knowledge, expertise and evidence in regulatory decision-making within a given institutional context. The underlying assumption is that, in the same way as civic epistemologies vary across polities, regulatory epistemologies also vary, not only along the lines of nations and political cultures, but also according to the specific regulatory and institutional contexts in which they are embedded.

In the EU, the tenets on which institutional knowledge creation stands have undergone a gradual process of codification in response to the lack of public trust that followed the bovine spongiform encephalopathy (BSE) and other food-related crises. As a result, a series of non-binding policy orientations and guidelines ${ }^{11}$ have sought to clarify the assumptions underpinning experts' involvement in EU regulatory activities. ${ }^{12}$ Among such assumptions, a primary role has been played by the risk analysis model, ${ }^{13}$ understood in its linear rather than iterative dimension, and thus entailing the separation between (scientific) risk assessment and (political) risk management. ${ }^{14}$ This understanding of the risk analysis model has represented the overarching framework within which other key elements of the EU's regulatory epistemology, including the precautionary principle, have been framed. The ensuing need to enforce the separation of risk assessment and risk management, and in particular to isolate the former from undue political influence, has been paired with efforts to define both the conditions for regulatory action in circumstances of scientific uncertainty ${ }^{15}$ and the requirements of "good regulatory expertise". The latter have been progressively identified in the standards of excellence, independence and transparency by the 1997 Commission Communication on consumer health and food safety; ${ }^{16}$ of accountability, plurality and integrity by the 2001 White Paper on European Governance, ${ }^{17}$ and of quality, openness and effectiveness by the 2002 Commission guidelines on the use of expertise. ${ }^{18}$

\footnotetext{
$10 \quad$ ibid, 251.

11 See European Commission, "Communication from the Commission on the Collection and Use of Expertise by the Commission: Principles and Guidelines", $\operatorname{COM}(2002) 713$ final; European Commission, "Science and Society Action Plan" (2002); European Commission, "Communication from the Commission on the Precautionary Principle", $\operatorname{COM}(2000) 1$ final; European Commission, "Communication from the Commission on Consumer Health and Food safety" COM(97)183 final.

12 For a discussion of the Commission's approach, see C Holst and JR Moodie, "Cynical or Deliberative? An Analysis of the European Commission's Public Communication on Its Use of Expertise in Policy-Making” (2015) 3(1) Politics and Governance 37.

13 See, among many, A Alemanno, "The Shaping of European Risk Regulation by Community Courts", The Jean Monnet Working Papers, no. 18/2008, 6; N Vareman and J Persson, "Why Separate Risk Assessors and Risk Managers? Further External Values Affecting the Risk Assessor qua Risk Assessor" (2010) 13(5) Journal of Risk Research 687.

14 The linear understanding of risk analysis is, however, neither intrinsic nor uncontroversial. See E Fisher, "Framing Risk Regulation: A Critical Reflection" (2013) 2 European Journal of Risk Regulation 125, and, in the context of the Codex Alimentarius Commission, Arcuri, supra, note 5, p 99.

15 European Commission, "Communication from the Commission on the Precautionary Principle", supra, note 11.

16 ibid.

17 European Commission, "European Governance - A White Paper”, DOC/01/10, 19.

18 European Commission, "Communication from the Commission on the Collection and Use of Expertise by the Commission”, supra, note 11 .
} 
The 2002 guidelines characterise "quality" as encompassing scientific excellence, integrity and pluralism. In particular, excellence is not limited to the academic canons of peer-reviewed publications, but also comprises practical knowledge; integrity entails a broad reading of independence, aimed not so much at neutralising the experts' personal background, but rather at "minimising the risk of vested interests distorting the advice proffered"; ${ }^{19}$ and pluralism aims at ensuring that a diversity of viewpoints is represented, including "differences in scientific approach, different types of expertise, different institutional affiliations, or contrasting opinions over the fundamental assumptions underlying the issue". ${ }^{20}$ Openness informs not only the selection of experts and the handling of results, but also the very way in which issues are framed, and it is coupled with proactive communication, within the limits represented by the protection of other competing interests (eg the quality of the deliberation and relevant public and private interests to confidentiality).

Such (non-binding) policy commitments are mirrored in (binding) legal provisions governing food governance in general and plant protection products in particular. Both Regulation 178/2002 (General Food Law, hereinafter GFL) ${ }^{21}$ and Regulation $1107 / 2009$ (Plant Protection Products Regulation, hereinafter PPP Regulation) ${ }^{22}$ implement the separation between risk assessment and risk management. ${ }^{23}$ The former establishes the EFSA and entrusts to it the provision of scientific advice and support in the food safety sector; ${ }^{24}$ the latter envisages a centralised authorisation for active substances, ${ }^{25}$ whereby the risk assessment phase is entrusted to the EFSA and the competent scientific authority of the RMS, while the European Commission, assisted by the PAFF committee, acts as risk manager on the basis of the scientific risk assessment and of "other factors legitimate to the matter under consideration", including, if relevant, the precautionary principle. ${ }^{26}$ The independence of risk assessors is guarded by Article 37 of the GFL ${ }^{27}$ and embedded in the design of the EFSA's governance structure. ${ }^{28}$ As the time of writing, ${ }^{29}$ the agency's management

$\begin{array}{ll}19 & \text { ibid, } 9 . \\ 20 & \text { ibid, } 9 . \\ 21 & \text { Regulation (EC) No. 178/2002 of the European Parliament and of the Council of } 28 \text { January } 2002 \text { laying down the }\end{array}$ general principles and requirements of food law, establishing the European Food Safety Authority and laying down procedures in matters of food safety, OJ L31, 1.2.2002, 1.

22 Regulation (EC) No. 1107/2009 of the European Parliament and of the Council of 21 October 2009 concerning the placing of plant protection products on the market and repealing Council Directives 797117/EEC and 91/414/EEC, OJ L309, 2411.2009, 1.

23 Art 6 GFL.

24 Arts 22-23 GFL.

25 Arts 7-13 PPP Regulation. See E Bozzini, Pesticide Policy and Politics in the European Union: Regulatory Assessment, Implementation and Enforcement (London, Palgrave Macmillan 2017), p 45.

26 Art 13 PPP Regulation.

27 According to Art 37 GFL, members of the EFSA's governing structure "shall undertake to act independently in the public interest", while members of its Scientific Committee and its Scientific Panel "shall undertake to act independently of any external influence".

28 See Section 2 GFL, and in particular the criteria and procedure for the appointment of Management Board and Scientific Panels members.

29 For the innovations introduced by Regulation (EU) 2019/1381 (applicable from March 2021) with regard to the EFSA's governance, see Section IV. 
board is composed of 14 members, appointed by the European Council, with the involvement of the EP and the European Commission, "so as to secure the highest standard of competence, a broad range of relevant expertise and, consistent with these, the broadest possible geographic distribution within the Union". It includes four members with a background in organisations representing consumers and "other interests in the food chain". ${ }^{30}$ The GFL's general commitment to transparency is enshrined in Article 10, while specific provisions concerning proactive disclosure, access to documents and exceptions to it are laid down in Articles 38, 39 and 41. The PPP Regulation provides further details as to the possibility for the applicant to request confidential treatment for part of the information submitted with the application dossier. ${ }^{31}$ It should be kept in mind that the PPP Regulation places the burden of proof as to the safety of the substance on the applicant: most of the scientific data on which the risk assessment is based are thus funded by and belong to the applicant, and are commissioned to private laboratories, in compliance with the Organisation for Economic Co-operation and Development (OECD) guidelines on Good Laboratory Practice.

The glyphosate dispute has put under strain several of these provisions. The next section characterises these tensions, starting from the EP's resolution approving the report of the PEST committee ${ }^{32}$ and from the Scientific Opinion of the Commission's Scientific Advice Mechanism (SAM). ${ }^{33}$ Based on a combined reading of the democratic and regulatory-scientific input into the debate, it argues that such tensions have developed along three main intertwined lines of conflict. Such lines concern the sources, the levels and the purposes of knowledge-making in the EU authorisation regime for active substances and equally relate to the assessment and to the management of risks.

\section{ThreE TENSIONS IN THE GLYPHOSATE SAGA}

\section{Sources}

The first line of tension concerns the scientific sources on which active substances' assessments are based, and in particular the reconciliation of privately generated knowledge with the public interest. The regulatory choice of placing the burden of proof on the applicant results in most scientific studies being privately funded and

\footnotetext{
30 Art 25(1) GFL.

31 Art 63 PPP Regulation. A presumption of confidentiality is established in favour of information, such as methods of manufacture, information on the complete composition of a product or the specification of impurity, whose disclosure may be particularly harmful to the producer. Confidentiality requests are assessed by the RMS and by the EFSA.

32 European Parliament, "Sustainable Use of Pesticides", European Parliament resolution of 12 February 2019 on the implementation of Directive 2009/128/EC on the sustainable use of pesticides (2017/2284(INI)), P8_TA-PROV(2019) 0082. Some of the tensions described in Section III have also been highlighted by the European Parliament Research Service in its implementation assessment of the PPP Regulation (against the criteria of relevance, coherence, effectiveness, efficiency and EU added value), European Parliament Research Service, "Regulation (EC) 1107/2009 on the Placing of Plant Protection Products on the Market, European Implementation Assessment", PE 615.668, April 2019.

33 Scientific Advice Mechanism (SAM), Group of Chief Scientific Advisors, "EU Authorisation Processes of Plant Protection Products - From a Scientific Point of View", Scientific Opinion 5/2018.
} 
generated, and possibly containing confidential information. Paradoxically, while such regulatory design is also an expression of precautionary-orientated considerations,${ }^{34}$ it has resulted in major concerns as to the risk assessments' quality and independence. In particular, Article 8 of the PPP Regulation defines the content of the application dossier, but does not provide any safeguard against the possibility of applicants choosing to exclude unfavourable studies. Being privately owned, they might therefore escape the subsequent peer review carried out by the national and EU risk assessor, to the detriment of the comprehensiveness of the evidentiary basis on which the risk assessment stands. Different alternatives have been considered throughout the glyphosate dispute. The most radical suggested that the safety of a substance should be assessed exclusively on the basis of published peer-reviewed literature and independent studies commissioned by public authorities, thus excluding by default privately generated studies ${ }^{35} \mathrm{~A}$ less radical approach envisaged strengthening public scrutiny over laboratory studies design (eg through audits and the establishment of a register of all commissioned studies ${ }^{36}$ and ensuring a balance between the weight of private and public studies in the risk assessment. ${ }^{37}$ The presence - and prevalence of private studies has also raised another related set of concerns as to public access to information, and in particular as to the appropriate balance to be struck between the public interest in access to EU institutions' documents, protected by Regulation 1049/2001 and, for environmental information, by Regulation 1367/2006, and the private interest in keeping commercially sensitive information confidential. ${ }^{38}$

\section{Levels}

The duality of levels involved in pesticides authorisation procedures has resulted in several "cracks" and blame-shifting between MS and the European Commission. Rather than enhancing the overall scientific quality and legitimacy of the regulatory process, the interlocking between centralised and decentralised phases has instead been seen as giving rise to inconsistencies and accountability gaps, ${ }^{39}$ to the detriment of the objectivity and the thoroughness of the procedure. Such duality runs through both risk assessment and risk management. As to the former, the scientific assessment of active substances is shared among MS and the EU insofar as the first assessment of the documents submitted by the applicant is carried out by the competent authority

\footnotetext{
34 European Commission, "Communication from the Commission on the Precautionary Principle", supra, note 11, para 6.4 .

35 See the European Citizens' Initiative registered as "Ban Glyphosate and Protect People and the Environment from Toxic Pesticides", available at <http://ec.europa.eu/citizens-initiative/public/initiatives/successful/details/2017/ 000002> (last accessed 7 February 2020) and the European Commission's response, European Commission, Communication from the Commission on the European Citizens' Initiative "Ban Glyphosate and Protect People and the Environment from Toxic Pesticides", C(2017) 8414 final, 12; see also the EP resolution "Renewing the Approval of the Active Substance Glyphosate" of 24 October 2017, para 8.

36 SAM, para 40; European Parliament, "Sustainable Use of Pesticides", supra, note 32, para 39.

37 European Parliament, "Sustainable Use of Pesticides", supra, note 32, paras 43, 45.

38 SAM, supra, note 33, para 2.5. See also E Korkea-Aho and P Leino, "Who Owns the Information Held by EU Agencies? Weed Killers, Commercially Sensitive Information and Transparent and Participatory Governance" (2017) 54(4) Common Market Law Review 1059.

39 SAM, supra, note 33, paras 2.2.2-2.2.3.
} 
in the RMS and subsequently by the EFSA. It is worth noting that when the approval of a substance is asked for the first time, the applicant is free to choose the RMS. Over time, this has resulted in significant asymmetries among MS, with only 11 out of 28 having been chosen as rapporteurs, and 4 being responsible for $80 \%$ of the applications, raising concerns as to the quality and the objectivity of the assessments carried out at the MS level. ${ }^{40}$ In cases of renewals of existing authorisations, on the other hand, the allocation of the application to an RMS is managed according to a centralised system, so that the possibility, materialised in the case of glyphosate, of the same RMS being in charge of both the first assessment and the renewal cannot be ruled out, again with concerns as to the objectivity and the transparency of the risk assessment. ${ }^{41}$

Risk management also presents elements of duality, mainly through the involvement of the PAFF committee, composed of MS representatives, according to the comitology regulation. While being aimed at ensuring $\mathrm{MS}$ ' control over the exercise of the European Commission's implementing powers, the comitology procedure has, notwithstanding the 2011 reform, been generally criticised for leading to a blurring of political responsibility between the European Commission and the MS. In the specific case of glyphosate, concerns have been raised as to its independence and accountability. On the one hand, the national representatives are not subject to specific rules concerning independence and conflicts of interest. On the other hand, the lack of transparency of the comitology phase, and especially of MS' votes in the European Committee, ${ }^{42}$ has repeatedly resulted in instrumental blame-shifting between MS and the European Commission, not only within the centralised phase of the authorisation, but also when it comes to the approval of the individual plant protection products, which takes place at the MS level. In particular, it has been pointed out that this opens the way to the chance "that scientific risk assessments are questioned when member states differ in decisions on PPPs [authorised at national level] for non-scientific reasons". ${ }^{43}$ The multiple shifts (between active substance and products, between centralised and decentralised risk assessors, between technical and political instances) do not seem to contribute to the achievement of a shared view as to the scientific and political merits of the case, but rather to a dilution of the mechanisms directed at holding both the European Commission and the MS to account for their decisions.

\section{Purposes}

The dispute surrounding glyphosate's reauthorisation has exposed a third, deeper line of conflict, which reaches beyond the area of plant protection products to affect the EU's overall approach to risk regulation in the food sector. ${ }^{44}$ As the SAM rightly highlighted, the latter is affected by the absence of a "shared, comprehensive and long-term EU vision

\footnotetext{
40 EP, para AL.

41 EP, para AK.

42 European Parliament, "Sustainable Use of Pesticides", supra, note 32, paras 77-78.

43 SAM, supra, note 33, para 2.2.3.

44 See also GC Leonelli, "The Glyphosate Saga and the Fading Democratic Legitimacy of European Union Risk Regulation" (2018) 25(5) Maastricht Journal of European and Comparative Law 582.
} 
for food production, including the role of Plant Protection Products therein", which in turn "hinders the development of a well-defined policy with clear objectives and views on risk acceptability". ${ }^{45}$ The ambiguities affecting the EU food policy's goals, and in particular their internal prioritisation, have had negative repercussions for both the assessment and the management of risks.

What has been criticised first and foremost is the vagueness of the criteria against which a substance's safety must be assessed. One of the main innovations introduced by the 2009 Regulation is the adoption of a set of "cut-off" criteria that active substances need to meet cumulatively in order to be considered for authorisation. Such criteria, as established in Article 4 of the PPP Regulation and further detailed in its Annex II(3), are meant to identify the properties that are deemed to have harmful effects on human or animal health (ie substances that are carcinogenic, mutagenic, toxic for reproduction or endocrine-disruptive) or unacceptable effects on the environment (ie substances that are persistent, bio-accumulative and toxic for the environment, persistent organic pollutants or very persistent and very bio-accumulative).

While clear thresholds and indicators have been set for some of these criteria (eg persistence), other are to be substantiated through a "weight of evidence determination". ${ }^{46}$ Not only has this entailed the risk of inconsistencies in their application, but it has also had repercussions for the risk assessment methods. Insofar as different methods may be more or less adequate to the achievement of a given set of policy priorities, as in the case of the choice between hazard- and risk-based approaches, ${ }^{47}$ the ambiguity of policy goals leaves the risk assessor in a condition of uncertainty as to the adequacy of the method adopted for the achievement of the preferred policy outcome. ${ }^{48}$ Ultimately, it "leaves the risk assessor to decide in practical terms what is acceptable and how the different objectives should be balanced", thus blurring the lines between the role - and the legitimacy - of the assessor and the manager, with a consequent misalignment of political accountability mechanisms, targeted at the decision-maker (risk manager) but structurally much less fit for the purpose of capturing the exercise of technical assessments.

\footnotetext{
45 SAM, supra, note 33, para 2.1.

46 SAM, supra, note 33, p 42. The "weight of evidence determination" approach is "a process in which evidence is integrated to determine the relative support for possible answers to a question". It comprises three steps: (1) assembling the evidence into "lines of evidence"; (2) weighing the evidence according to its reliability, relevance and consistency; and (3) integrating the evidence. EFSA Scientific Committee, A Hardy, D Benford, T Halldorsson, MJ Jeger, HK Knutsen, S More, H Naegeli, H Noteborn, C Ockleford, A Ricci, G Rychen, JR Schlatter, V Silano, R Solecki, D Turck, E Benfenati, QM Chaudhry, P Craig, G Frampton, M Greiner, A Hart, C Hogstrand, C Lambre, R Luttik, D Makowski, A Siani, H Wahlstroem, J Aguilera, J-L Dorne, A Fernandez Dumont, M Hempen, S Valtueña Martínez, L Martino, C Smeraldi, A Terron, N Georgiadis and M Younes, "Scientific Opinion on the Guidance on the Use of the Weight of Evidence Approach in Scientific Assessments" (2017) 15(8) EFSA Journal 4971, 3. The opinion (10) observes how, while in some cases it may be concluded that the evidence supports only one answer with full certainty, in most cases "multiple answers remain possible, with differing levels of support. In such cases, the conclusion should state the range of answers that remain possible, and not be reduced to a single answer unless a threshold level of support for conclusions has been agreed with decision-makers, because this involves risk management considerations".

47 Far from being merely technical, the choice between hazard- and risk-based approaches reflects different views as to how risks should be assessed, and in particular as to whether exposure should be taken into account, which in turn are deemed to entail different consequences in terms of efficiency, costs and levels of protection. See SAM, supra, note 33, p 41.

48 SAM, supra, note 33 , para 2.1.
} 


\section{The General Food Law reform: managing pesticides through RISK ASSESSMENT?}

In June 2019, the proposed reform of the GFL was approved. ${ }^{49}$ It is the combined outcome of the "regulatory fitness and performance programme" that the European Commission carries out according to the better regulation agenda, and of the public concerns raised by the glyphosate dispute, in particular by the "Ban Glyphosate" ECI. ${ }^{50}$ The regulation addresses "the transparency and sustainability of the EU risk assessment in the food chain", where sustainability reads in institutional rather than in environmental terms, and risk communication.

The tensions examined under Section III.1 on sources of knowledge are addressed through a reconsideration of the rules implementing the principles of quality and openness. As to quality, the reform's overall approach is to broaden the range of evidence considered, so to ensure that all of the relevant knowledge is gathered and assessed and that no unfavourable data are withheld by the applicant. It establishes the mandatory registration of all of the studies commissioned to private laboratories with a view to applying for an authorisation under EU food law. ${ }^{51}$ The obligation falls both on the commissioning business operator and on EU-based laboratories, so as to enable cross-checking. Once the dossier is submitted (and published), the EFSA will hold a public consultation so as to expand its information basis beyond that provided by the private applicants. ${ }^{52}$ A specific procedure is envisaged for the renewals, where more information on the substance might be available: in these cases, the pre-submission phase, whereby the planned studies have to be notified to the EFSA, is mandatory, followed by a public consultation and by systematic advice by the agency. A final, and exceptional, innovation is the possibility for the European Commission to ask the EFSA to commission additional studies when the available evidence needs to be verified, such as in cases of serious controversies or conflicting scientific results. While aimed at ensuring the quality of the scientific evidence relied on, this instrument should be kept separate from the already envisaged possibility for the EFSA to commission "scientific studies for the performance of its mission". ${ }^{33}$ The latter falls under risk assessment, and the decision as to whether to make use of it falls within the EFSA's sphere of discretion. The new Article 32e, on the other hand, pertains to risk management: it is activated at the European Commission's discretion, within the limits of proportionality, and is linked to the presence of issues of high societal importance, which might result in the need to commission studies whose scope goes beyond the evidence at stake. ${ }^{54}$ It therefore has the potential to represent a bridge between the scientific and the societal aspects of pesticides authorisation and,

\footnotetext{
49 Regulation (EU) 2019/1381 of the European Parliament and of the Council of 20 June 2019 on the transparency and sustainability of the EU risk assessment in the food chain and amending Regulations (EC) No. 178/2002, (EC) No. 1829/ 2003, (EC) No. 1831/2003, (EC) No. 2065/2003, (EC) No. 1935/2004, (EC) No. 1331/2008, (EC) No. 1107/2009, (EU) 2015/2283 and Directive 2001/18/EC, OJ L231, 6.9.2019, 1.

50 As expressly acknowledged in Recital 24 of the Regulation.

51 Art 1(4) Regulation 1381/2019, inserting Art 32b into the GFL.

52 Art 1(4) Regulation 1381/2019, inserting Art 32c into the GFL.

53 Art 32 GFL.

54 See Regulation 1381/2019, Explanatory memorandum, 11.
} 
additionally, to mitigate, in exceptional cases, the prevalence of industry-originated studies. ${ }^{55}$

A second strategy envisaged by the reform in order to foster the quality of the assessment concerns the establishment of a voluntary pre-submission phase, with the purpose of ensuring that the applicant is aware of and can comply with the requirements relating to the content of the authorisation applications (therefore not the study design). ${ }^{56}$ Compliance is also ensured through audits carried out by the European Commission on the quality of the studies, and in particular on the reproducibility of their results.

Openness, on the other hand, is pursued through a reconsideration of the transparency regime applicable to the application documents, in terms of both content and procedure. In particular, the EFSA will publish all supporting data and information ${ }^{57}$ considered when assessing the dossier; when confidentiality claims are raised by the applicant, the applicant will have to submit a non-confidential and a confidential version of the allegedly sensitive information: the former will be published, the latter will be assessed individually by the EFSA within a tight time frame. ${ }^{58}$ The cases in which confidential treatment is allowed "upon verifiable justification" is amended so as to specify the types of information to which it applies, including manufacturing methods, information on the composition of the product and other commercial information. ${ }^{59}$ While this will surely increase the EFSA's workload and the amount of information disclosed, it can be wondered whether it will actually alter the "ownership" paradigm, ${ }^{60}$ since the steering (ie the initial flagging of confidential information) remains the applicant's responsibility.

The tensions considered under Section III.2 (ie those relating to the levels of government involved) are addressed from the perspective of the sustainability of the EFSA's organisation and functioning, with a view to fostering its effectiveness. In particular, the reform strengthens MS' involvement in the Agency's governance. On the one hand, the EFSA's management board composition will change so to include MS representatives ${ }^{61}$ in line with the other decentralised agencies. ${ }^{62}$ The whole representative dimension of the management board is enhanced: besides MS representatives, the board will also include one member appointed by the EP and four representing civil society and food chain interests, now specifically - and equally - allocated to consumer organisations, environmental non-governmental organisations, farmers and industry. On the other hand, the enhancement of MS involvement also relates to scientific cooperation and to the EFSA's scientific

\footnotetext{
55 It should, however, be kept in mind that the application of this provision is not meant to alter the principle that the burden to prove active substances' compliance with legislative requirements is on the industry. Ibid.

56 Art 32a as inserted by Regulation 1381/2019.

57 Art 38(c) as inserted by Regulation 1381/2019.

58 Ten weeks according to Art $39 \mathrm{~b}$ as inserted by Regulation 1381/2019.

59 Art 39(2) as inserted by Regulation 1381/2019.

60 E Korkea-Aho and P Leino, supra, note 38.

61 Art 28(5) GFL as amended by Regulation 1381/2019.

62 Joint Statement of the European Parliament, the Council of the EU and the European Commission on decentralised agencies, 2012, available at <https://europa.eu/european-union/sites/europaeu/files/docs/body/joint_statement_and_ common_approach_2012_en.pdf> (last accessed 7 February 2020).
} 
governance: the appointment of the members of the EFSA's scientific panels will now be based on MS proposals, ${ }^{63}$ keeping in mind that the nominated experts should present a high level of scientific expertise in the relevant field, be independent ${ }^{64}$ and ensure that the broadest possible geographical distribution is achieved. ${ }^{65}$

The reform seems to pursue multiple goals. Its stated objectives are to "improve the governance of and strengthen the scientific cooperation of Member States with and their involvement in the EFSA", and to "strengthen the ability of EFSA to maintain a high level of scientific expertise in the different areas of its work, especially its capacity to attract excellent scientists to be members of its Scientific Panels", thus addressing the quality and the effectiveness of the EFSA's action. In addition, it can be argued that the measures could also have a legitimacy-enhancing function: an increased MS engagement with the centralised phase of risk assessment could in fact contribute to closing the gap between the national and EU phases of the procedure, to the benefit of the acceptance of EU's risk assessments at the national level. At the same time, the reform does not seem to present elements of concern as to a risk of the EFSA's politicisation. MS' representatives in the management board must fulfil strict appointment criteria (and in particular ensure "high competence in the area of food safety risk assessment as well as competences in the food chain safety legislation and policy"), thus being clearly characterised as risk assessors, and act "independently in the public interest". 66

While the GFL reform addresses the tensions concerning the sources and the levels of EU knowledge-making, considerations on its purposes are nowhere to be found. None of the amendments introduces substantive measures aimed at disentangling the ambiguities between the different goals pursued by the EU food law or at clarifying the desired level of protection. Similarly, although the tensions discussed above relate equally to the assessment and the management of risks, the reform is mainly - and explicitly so addressed at the risk assessment and at the risk communication phases. The only exception is represented by the risk management measure envisaged in Article 32e GFL (the possibility for the European Commission to request verification studies in exceptional cases), which, as discussed above, might enhance the iterative dimension of risk analysis.

\section{The EU's REgUlatory EPISTEMOLOGY AFTER GLYPHOSATE}

The previous sections have sought to understand whether and how the glyphosate dispute has led to any development in the epistemic assumptions upon which the EU's food governance rests (ie its regulatory epistemology). In so doing, it has provided a reading of the dispute based on three main lines of tension - respectively, concerning the sources, levels and purposes of EU knowledge-making - and has then considered how they have been addressed by the recently approved reform of the GFL.

63 Art 28(5a)(a)-(c) as amended by Regulation 1381/2019.

64 Art 28(5a)(d) as amended by Regulation 1381/2019.

65 Art 28(5a)(e) as amended by Regulation 1381/2019.

66 Art 25 GFL as amended by Regulation 1381/2019. As to the scientific panels' members, the current independence criteria are maintained, and specific provisions are put in place requiring Member States to ensure the concrete means for experts to act independently. 
The picture emerging from such analysis is one of continuity rather than one of radical change: neither the risk analysis model nor the principles on good regulatory expertise have been fundamentally affected. ${ }^{67}$ At a closer look, however, it is possible to capture some further nuances in the ways in which such assumptions have been restated. The risk analysis model has not been significantly questioned and, although it has been shown that the conflicts triggered by glyphosate relate to both its scientific and its management branch, only the former has been targeted by the GFL reform (with the exception of the possibility for the European Commission acting as a risk manager to request verification studies). It has been noted how the glyphosate dispute more generally has resulted in a missed opportunity for the European Commission to implement the concept of socially acceptable risk, ${ }^{68}$ and the reform of the GFL does not seem to offer elements to the contrary. Within this general picture, a counter-trend should, however, be highlighted: the strengthening of MS' involvement in the EFSA's governance and the inclusion of the EP's representatives in its management board can be seen as a development that is capable of broadening the range of concerns considered by the risk assessors, to the benefit not only of the effectiveness of the procedure, but also of its legitimacy.

Similarly, the guiding principles of quality, openness and effectiveness have not been affected at their core, but they emerge from the GFL reform with a greater degree of refinement. The rules implementing the principles of quality and openness (in particular with regard to scientific studies) remain based on the assumption that the burden of proof shall fall on the applicant. While not questioning it, the GFL reform represents an effort to realign the private origin of studies with the public interest, both through the possibility for the European Commission to exceptionally ask the EFSA to commission verification studies and through widening the evidentiary basis upon which the assessment stands and the public's access to it. Two recent decisions of the General Court may, however, cast doubt on whether such efforts have been sufficiently ambitious, at least with regard to environmental information. ${ }^{69}$ The reach of the right to access environmental information, as established by the General Court for the scientific studies concerning active substances' toxicity and carcinogenicity, is in fact broader than the one enshrined in the new Article 39 of the GFL.

Based on the legal analysis of the GFL reform, the political earthquake determined by glyphosate has not resulted in a comparable development of the EU's regulatory epistemology, but rather in a refinement of the rules that articulate it into legal commitments. In addition, it has had the merit of exposing the tensions that lie under the surface of EU risk regulation and of challenging - sometimes radically - the

\footnotetext{
67 See also the Court of Justice's decision in Case C-616/17, Blaise and Others [2019] ECLI:EU:C:2019:800, confirming the validity of the general regulatory architecture of the PPP Regulation. A Donati, "The Glyphosate Saga, A Further but Not a Final Step: The CJEU Confirms the Validity of the Regulation on Plant Protection Products in Light of the Precautionary Principle" (2020) European Journal of Risk Regulation (epub ahead of print). 68 Leonelli, supra, note 44, p 604.

69 Case T-716/14, Anthony C Tweedale v European Food Safety Authority [2019] ECLI:EU:T:2019:141; Case T-329/ 17, Heidi Hautala and Others v European Food Safety Authority [2019] ECLI:EU:T:2019:142. See M Morvillo, "The General Court Orders Disclosure of Glyphosate-related Scientific Studies: Tweedale, Hautala, and the Concept of Environmental Information in the Context of Plant Protection Products" (2019) 10(2) European Journal of Risk Regulation 419.
} 
regulatory design that embodies them. A full appreciation of its impact will have to wait for the next renewal of the active substance, expected by December 2022. In the meantime, a double testing ground will be provided, on the one hand, by the outcome of the regulatory fitness and performance programme of the PPP Regulation, currently underway, and, on the other hand, by future (and highly foreseeable) legal challenges to the EFSA's decisions on requests for public access to scientific studies. 